\title{
Psychiatric paternalism between Scylla and Charybdis Bettina Schöne-Seifert
}

Address: Lehrstuhl für Medizinethik, Institut für Ethik, Geschichte \& Theorie der Medizin, Universität Münster, Von-Esmarch-Straße 62, 48149

Münster, Germany

from WPA Thematic Conference. Coercive Treatment in Psychiatry: A Comprehensive Review

Dresden, Germany. 6-8 June 2007

Published: 19 December 2007

BMC Psychiatry 2007, 7(SuppI I):SII9 doi:I0.II86/I47I-244X-7-SI-SII9

This abstract is available from: http://www.biomedcentral.com/I47I-244X/7/SI/SII9

(c) 2007 Schöne-Seifert; licensee BioMed Central Ltd.

As much as strong medical paternalism should never be exercised, some weak paternalism towards patients is, on the contrary, part of physicians' and society's moral obligation. So far, this is a widely consented position in medical ethics. What then are the defining and the justifying conditions for legitimate weak paternalism in psychiatry? In this presentation it is argued in favor of three necessary and jointly sufficient conditions for ethically acceptable/ obligatory paternalism: (1) the patient must lack specific competency to evaluate his or her treatment options in a sufficiently autonomous way; (2) there must not be evidence that the patient had, in a former healthy state, been opposed to weak paternalism; (3) there must exist treatment options with a truly acceptable cost-benefit balance, that cannot be postponed until regain of competency, without harming the patient. Even if this seems a plausible normative frame, there remain difficulties in detail for both conceptual ethical theory and psychiatric practice. Among them are: assessing patient competency, avoiding undue control in patient preference formation, identifying third parties' interests, and evaluating treatment options. For psychiatry's self-understanding, societal image, and acceptance by patients and their families, it seems important to tackle these issues so as to get a coherent and transparent picture of the justification and limits of psychiatric paternalism. 